\title{
Studi Demografi dan Ekonomi Penduduk Desa Sebulu Modern, Kecamatan Sebulu, Kabupaten Kutai Kartanegara, Provinsi Kalimantan Timur Tahun 2019
}

\author{
Study of Demography and Economic in Sebulu Modern Village, Sebulu Sub District, \\ Kutai Kartanegara District, East Kalimantan Province 2019
}

\author{
Wartomo $^{* 1}$, Abdul Rasyid Zarta ${ }^{2}$, M. Fikri Hernandi ${ }^{1}$ \\ ${ }^{1}$ Program Studi Pengolahan Hasil Hutan, Politeknik Pertanian Negeri Samarinda, Indonesia. \\ ${ }^{2}$ Program Studi Rekayasa Kayu, Politeknik Pertanian Negeri Samarinda, Indonesia. \\ ${ }^{*}$ Correspondence Author: wartomo63.phh@gmail.com
}

\begin{abstract}
ABSTRAK
Desa Sebulu Modern merupakan desa pedalaman, terletak di bantaran Sungai Mahakam, dan aksesibilitasnya baik. Desa yang mayoritas penduduknya bekerja sebagai petani dan wiraswasta/dagang ini mayoritas penduduknya adalah Suku Kutai. Tujuan penelitian untuk mengetahui kondisi sosial masyarakat Desa Sebulu Modern yang meliputi demografi desa, ekonomi dan budaya masyarakat desa. Penelitian ini menggunakan data primer dan sekunder, dilakukan dengan wawancara terstruktur, pengolahan data secara tabulasi, dan dianalisis secara statistik dan penafsiran. Hasil penelitian menunjukkan bahwa kondisi demografi Desa Sebulu Modern yaitu jumlah penduduk 4.224 jiwa, sex rasio 104,26 ; kepadatan penduduk 67,40 jiwa/ $/ \mathrm{Km}^{2}$, usia produktif $60,39 \%$; angka beban tanggungan 65,58\%; mayoritas beragama Islam, pendidikan penduduk tamat SLTA ke atas sebanyak $23,89 \%$; mata pencaharian penduduk mayoritas adalah petani dan wiraswasta/dagang, tingkat emigrasi sebesar penduduk 5,92; tingkat imigrasi penduduk 3,55; tingkat kelahiran bayi 10,65 ; tingkat kematian penduduk 4,73; dan pola migrasi penduduk secara sirkel, tingkat partisipasi angkatan kerja sebesar $55,14 \%$ dan tingkat pengangguran sebesar $14,46 \%$. Kondisi ekonomi masyarakat Desa Sebulu Modern yaitu pendapatan penduduk perkapita pertahun sebesar Rp 13.159.528,- tergolong tidak miskin, kepemilikan lahan berdasarkan warisan dan beli dari orang lain, serta kesempatan kerja 38,15\% dan kesempatan berusaha 47,38\%. Kondisi budaya masyarakat Desa Sebulu Modern yaitu mayoritas penduduk Suku Kutai, adat istiadat yang berlaku adalah adat istiadat Kutai, serta pengelolaan desa dipimpin oleh Kepala Desa dan Ketua Adat.
\end{abstract}

Kata Kunci: Demografi, Desa Sebulu Modern, Kalimantan Timur

\begin{abstract}
Sebulu Modern Village is an inland village, located on the banks of the Mahakam River, and its accessibility is good. The village majority population is working as farmers and entrepreneurs/trade and the majority of the population is Kutai Ethnic. The research objective was to determine the social conditions of the Sebulu Modern Village community which included village demography, economy and culture of the village community. This study uses primary and secondary data, carried out by structured interviews, tabulation data processing, and statistically analyzed and interpreted. The results showed that the demographic conditions of Sebulu Modern Village were 4,224 people, sex ratio 104.26; population density of 67.40 people/Km2, productive age $60.39 \%$; dependency expense figure of $65.58 \%$; the majority are Muslim, education of residents graduating from senior high school and above is $23.89 \%$; the livelihoods of the majority of the population are farmers and selfemployed/trade, the emigration rate is 5.92; immigration rate of 3.55; baby birth rate 10.65; population mortality rate 4.73; and the pattern of circulating population migration, the labor force participation rate of $55.14 \%$ and the unemployment rate of $14.46 \%$. The economic conditions of the Sebulu Modern Village community are income per capita per year of Rp. 13,159,528, - classified as not poor, ownership of land based on inheritance and buying from others, and employment opportunities $38.15 \%$ and business opportunities $47.38 \%$. The cultural conditions of Sebulu Modern Village community are population majority is Kutai Ethnic, prevailing customs are Kutai customs, and village management led by Village Head and Customary Chair.
\end{abstract}

Keywords: Demography, Sebulu Modern Village, East Kalimantan 


\section{PENDAHULUAN}

Desa Sebulu Modern merupakan salah satu desa di Kecamatan Sebulu, Kabupaten Kutai Kartanegara, Provinsi Kalimantan Timur. Desa ini terletak di bantaran Sungai Mahakam dan tergolong desa pedalaman. Di sekitar desa ini beroperasi beberapa perusahaan seperti perusahaan pertambangan batubara, perkebunan kelapa sawit dan kehutanan. Penduduk desa ini mayoritas Suku Kutai dan matapencaharian utama adalah sebagai petani dan wiraswasta/dagang, sehingga kehidupan masyarakat desa ini tergantung pada alam (sumberdaya alam) dan keberadaan perusahaan.

Jalan-jalan desa di Sebulu Modern dan jalan antar desa yang menghubungkan desa ini dengan desa sekitar, semuanya berupa jalan semen. Jarak Desa Sebulu Modern dengan Ibukota Kecamatan Sebulu sekitar $4 \mathrm{Km}$ dan dengan Ibukota Kabupaten Kutai Kartanegara sekitar 20 $\mathrm{Km}$. Jalan yang menghubungkan Sebulu Modern dengan ibukota kecamatan dan ibukota kabupaten berupa jalan semen dengan kondisi baik. Jarak tempuh dari Desa Sebulu Modern ke Ibukota Kabupaten sekitar 45 menit menggunakan kendaraan roda dua atau roda empat.

Keberadaan sarana transportasi sangat erat hubungannya dengan aksesibilitas suatu daerah. Semakin beragam jenis dan jumlahnya pada suatu daerah, aksesibilitasnya semakin baik. Alat transportasi yang biasa digunakan oleh warga Desa Sebulu Modern adalah sepeda motor dan mobil milik pribadi. Angkutan umum berupa kendaraan roda empat tidak ada, yang ada adalah ojek.

Pada awalnya desa ini adalah desa tertinggal, namun dengan aktivitas perusahaan terjadi perubahan terhadap kehidupan sosial ekonomi kemasyarakatan. Perubahan yang terjadi terlihat secara signifikan namun signifikansi perubahan belum terukur berdasarkan data ataupun hasil kajian yang dapat dipertanggungjawabkan.

Oleh karena itu untuk menjawab pernyataan tersebut di atas maka dilakukan studi ini dengan tujuan mengetahui demografi dan ekonomi penduduk Desa Sebulu Modern Tahun 2019, yang terdiri dari struktur penduduk, proses penduduk, tenaga kerja, tingkat pendapatan penduduk, ekononi sumberdaya alam, dan perekonomian lokal atau regional.

Hasil yang diharapkan dari penelitian ini adalah dengan mengetahui demografi penduduk dan ekonomi masyarakat Desa Sebulu Modern, yang dapat dipakai sebagai dasar pemerintah untuk pengambilan keputusan dalam pengelolaan desa.

\section{METODE PENELITIAN}

\section{Tempat dan Waktu}

Penelitian ini dilakukan di Desa Sebulu Modern, Kecamatan Sebulu, Kabupaten Kutai Kartanegara, Provinsi Kalimantan Timur. Pengambilan data dilakukan pada tanggal 12 sampai dengan 20 Juni 2019, pengolahan data dan pelaporan tanggal 20 sampai dengan 30 Juni 2019.

\section{Bahan dan Alat}

1. Kuisioner untuk Kepala Desa Sebulu Modern

2. Kuisioner untuk Penduduk Desa Sebulu Modern

3. Data Kependudukan dan Monografi Desa Sebulu Modern Tahun 2019

4. Alat tulis menulis

\section{Prosedur Penelitian}

1. Melakukan wawancara dan pengisian kuisioner dengan Kepala Desa Sebulu Modern dan Aparat Desa untuk mendapatkan data:

a. Demografi yang terdiri dari struktur penduduk, proses penduduk dan tenaga kerja

b. Ekonomi yang terdiri dari ekonomi rumah tangga (tingkat pendapatan penduduk), ekonomi sumber daya alam, serta perekonomian lokal dan regional

2. Melakukan wawancara dan pengisian kuisioner dengan penduduk yaitu 60 kepala keluarga (sampel sekitar 5\%) untuk mendapatkan data primer ekonomi masyarakat yang meliputi pendapatan penduduk dan ekonomi sumber daya alam 
3. Meminta data kependudukan dan Monografi Desa Sebulu Modern Tahun 2019 kepada Aparat Desa untuk mendapatkan data primer dan sekunder.

\section{Pengolahan Data}

Data yang telah dikumpulkan diolah terlebih dahulu melalui cara tabulasi. Selanjutnya dilakukan analisis non statistik yaitu dengan melakukan penafsiraan hasil tabulasi secara logika untuk sosial dan budaya. Selain itu juga dilakukan analisis statistik untuk parameter kependudukan, pendapatan dan perekonomian.

\section{HASIL DAN PEMBAHASAN}

\section{A. Demografi}

1. Struktur Penduduk

a. Struktur Penduduk Berdasarkan Jenis Kelamin dan Kepadatan Penduduk.

Struktur penduduk berdasarkan jenis kelamin dan kepadatan penduduk Desa Sebulu Modern secara rinci tersaji dalam Tabel 1 di bawah ini.

Tabel 1. Struktur Penduduk Desa Sebulu Modern Berdasarkan Jenis Kelamin dan Kepadatan Penduduk.

\begin{tabular}{lc}
\hline \multicolumn{1}{c}{ Keadaan Penduduk } & Keterangan \\
\hline Jumlah Kepala Keluarga (KK) & 1.181 \\
Jumlah Penduduk (jiwa) & 4.224 \\
Laki-laki (jiwa) & 2.156 \\
Perempuan (jiwa) & 2.068 \\
Sex-rasio & 104,26 \\
Jumlah jiwa/KK & 3,58 \\
Luas desa $\left(\mathrm{Km}^{2}\right)$ & 62,6675 \\
Kepadatan (jiwa/ $/ \mathrm{Km}^{2}$ ) & 67,40 \\
\hline
\end{tabular}

Sumber: Anonim (2019) dan Data Primer Desa Sebulu Modern (2019)

Desa Sebulu Modern tergolong desa sedang menurut Anonim (1960) bahwa desa kecil $<500 \mathrm{KK}$, sedang $500-1.500$ KK, besar $>1.500 \mathrm{KK}$ ). Setiap KK rata-rata beranggotakan 3 - 4 jiwa. Sex rasio penduduk 104,26 artinya setiap 100 perempuan terdapat 104 - 105 laki-laki, dengan demikian rata-rata penduduk lakilaki relatif lebih banyak.

Kepadatan penduduk Desa Sebulu Modern adalah $67,40 \mathrm{jiwa} / \mathrm{Km}^{2}$, tergolong kurang padat (Anonim,1960) bahwa kepadatan penduduk tidak padat: $<50$ jiwa/ $/ \mathrm{Km}^{2}$, kurang padat: 51-250 jiwa/ $/ \mathrm{Km}^{2}$, cukup padat: $251-400$ jiwa/ $/ \mathrm{Km}^{2}$, sangat padat: $>400$ jiwa $/ \mathrm{Km}^{2}$ ).

b. Struktur Penduduk Berdasarkan Kelompok Umur

Struktur umur penduduk Desa Sebulu Modern berstruktur tidak berimbang antara umur anak-anak, remaja, dewasa dan manula. Secara rinci dapat dilihat pada Tabel 2 di bawah ini.

Tabel 2. Struktur Penduduk Desa Sebulu Modern Berdasarkan Kelompok Umur.

\begin{tabular}{ccc}
\hline Kelompok Umur (tahun) & Jiwa & $\%$ \\
\hline $0-4$ & 399 & 9,45 \\
$5-9$ & 433 & 10,25 \\
$10-14$ & 445 & 10,54 \\
$15-19$ & 486 & 11,51 \\
$20-24$ & 425 & 10,06 \\
$25-29$ & 385 & 9,11 \\
$30-34$ & 345 & 8,17 \\
$35-39$ & 327 & 7,74 \\
$40-44$ & 288 & 6,82 \\
$45-49$ & 228 & 5,40 \\
$50-54$ & 170 & 4,02 \\
$55-59$ & 123 & 2,91 \\
60 ke atas & 396 & 9,38 \\
\hline Jumlah & 4.224 & 100 \\
\hline
\end{tabular}

Sumber: Anonim (2019)

Mengacu data di atas bahwa penduduk Sebulu Modern dengan kelompok umur 0 - 14 tahun (anak-anak) sebanyak 1.277 jiwa $(30,23 \%)$, umur $15-$ 59 tahun sebanyak 2.551 jiwa $(60,39 \%)$, dan umur 60 tahun ke atas (manula) sebanyak 396 jiwa $(9,38 \%)$. Kelompok umur 0 - 14 tahun dan 60 tahun ke atas merupakan umur tidak produktif, serta kelompok umur 15 - 59 tahun tergolong umur produktif.

Dengan diketahuinya proporsi antara umur produktif dan tidak produktif maka Angka Beban Tanggungan (ABT) penduduk Sebulu Modern adalah 65,58\%. Hal ini berarti setiap 100 orang umur produktif menanggung 65 - 66 orang umur tidak produktif, dan tergolong tinggi. Menurut Munir (2014) yang menjelaskan bahwa kelas rendah: $\mathrm{ABT}<30 \%$, sedang: ABT $30-40 \%$, dan tinggi: $A B T>40 \%$. Jika dipilah untuk anak-anak dan manula, maka ABT kelompok anak-anak adalah 50,06\% dan kelompok manula $15,52 \%$. Hal ini 
dapat dipahami mengingat struktur umur penduduk pada kelompok umur anak-anak jauh lebih tinggi dari manula.

\section{c. Struktur Penduduk Berdasarkan Agama}

Agama yang dianut penduduk Desa Sebulu Modern secara rinci dapat dilihat pada Tabel 3 di bawah ini.

Tabel 3. Struktur Penduduk Desa Sebulu Modern Berdasarkan Agama.

\begin{tabular}{|c|c|c|}
\hline Agama & Jiwa & $\%$ \\
\hline Islam & 4.217 & 99,83 \\
\hline Protestan & 7 & 0,17 \\
\hline Jumlah & 4.224 & 100 \\
\hline $\begin{array}{l}\text { Sumber: Data } \\
\text { Modern (2019) }\end{array}$ & Primer & Desa \\
\hline
\end{tabular}

Sarana ibadah yang ada di Sebulu Modern secara lengkap dapat dilihat pada tabel di bawah ini.

Tabel 4. Sarana Ibadah Desa Sebulu Modern.

\begin{tabular}{lc}
\hline Sarana Ibadah & Keterangan \\
\hline Masjid & 3 buah \\
Mushala & 3 buah \\
Gereja & 1 buah \\
\hline
\end{tabular}

Sumber: Data Primer Desa Sebulu Modern (2019)

\section{d. Struktur Penduduk Berdasarkan Pendidikan}

Tingkat pendidikan penduduk Sebulu Modern secara lengkap tersaji pada Tabel 5 di bawah ini.

Tabel 5. Struktur Penduduk Desa Sebulu Modern Berdasarkan Pendidikan.

\begin{tabular}{lcc}
\hline \multicolumn{1}{c}{ Tingkat Pendidikan } & Jiwa & $\%$ \\
\hline Belum sekolah, masih & & \\
sekolah, tidak tamat SD & 1.961 & 46,43 \\
Tamat SD/sederajat & 702 & 16,62 \\
Tamat SLTP/sederajat & 552 & 13,07 \\
Tamat SLTA/sederajat & 945 & 22,37 \\
Diploma/Sarjana & 64 & 1,52 \\
\hline Jumlah & 4.224 & 100 \\
\hline
\end{tabular}

Sumber: Anonim (2019) dan Data Primer Desa Sebulu Modern (2019)

Penduduk Sebulu Modern yang minimal tamat SD/sederajat sebanyak 2.263 jiwa $(53,57 \%)$, dan yang tamat minimal SLTA/sederajat sebanyak 1.009 jiwa $(23,89 \%)$. Tamat SLTA merupakan program Pemerintah Kalimantan Timur yaitu wajib pendidikan 12 tahun, maka tingkat pendidikan masyarakat Sebulu Modern tergolong rendah.

Fasilitas pendidikan yang ada di Sebulu Modern dapat dilihat pada Tabel 6 di bawah ini.

Tabel 6. Fasilitas Pendidikan Serta Rasio Guru dan Murid Di Sebulu Modern.

\begin{tabular}{lcccc}
\hline Fasilitas & Unit & $\begin{array}{c}\sum \text { murid } \\
\text { (orang) }\end{array}$ & $\begin{array}{c}\sum \text { Guru } \\
\text { (orang) }\end{array}$ & $\begin{array}{c}\text { Rasio } \\
\text { Guru } \\
\text { dan Murid }\end{array}$ \\
\hline TK & 3 & 50 & 17 & $1: 3$ \\
SD & 5 & 480 & 60 & $1: 8$ \\
\hline
\end{tabular}

Sumber: Anonim (2019) dan Data Primer Desa Sebulu Modern (2019)

Ketersediaan guru tingkat TK dan SD tergolong mencukupi karena rasio guru dan murid masih di atas 1:20.

e. Struktur Penduduk Berdasarkan Pekerjaan

Penduduk Sebulu Modern sebagian besar bekerja sebagai petani dan wiraswasta/dagang. Secara lengkap, pekerjaan penduduk Sebulu Modern dapat dilihat pada tabel berikut.

Tabel 7. Struktur Penduduk Desa Sebulu Modern Berdasarkan Pekerjaan.

\begin{tabular}{lcc}
\hline \multicolumn{1}{c}{ Pekerjaan } & Jiwa & $\%$ \\
\hline Petani & 467 & 33,60 \\
Nelayan & 5 & 0,36 \\
Tukang & 82 & 5,90 \\
Wiraswasta/dagang & 410 & 29,50 \\
Jasa (buruh, ojek, & 64 & 4,60 \\
assist. RT, dll) & 83 & 5,97 \\
Karyawan Perusahaan & 214 & 15,40 \\
Buruh lepas, honorer & 65 & 4,68 \\
Aparatur Sipil Negara & 1.390 & 100 \\
\hline Jumlah &
\end{tabular}

Sumber: Anonim (2019) dan Data Primer Desa Sebulu Modern (2019)

Berdasarkan tabel di atas, jumlah penduduk yang bekerja/berusaha sebanyak 1.390 jiwa yang terdiri dari penduduk bekerja sebanyak 620 jiwa (pekerjaan petani, nelayan, ASN dan karyawan perusahaan) dan penduduk berusaha sebanyak 770 jiwa (pekerjaan sebagai tukang, jasa, buruh dan wiraswasta/dagang). 


\section{Proses Penduduk}

\section{a. Tingkat Migrasi Penduduk}

Berdasarkan data Desa Sebulu Modern pada Tahun 2018, tingkat migrasi penduduk secara lengkap dapat dilihat pada Tabel 8. Data perhitungan tingkat migrasi penduduk mengacu pada Ahmadi (2003).

Tabel 8. Tingkat Migrasi Penduduk Desa Sebulu Modern Tahun 2018-2019

\begin{tabular}{lc}
\hline \multicolumn{1}{c}{ Keadaan Penduduk } & Keterangan \\
\hline Jumlah penduduk pendatang & 25 jiwa \\
Jumlah penduduk yang pindah & 15 jiwa \\
Jumlah penduduk & 4.224 jiwa \\
Tingkat emigrasi penduduk & 5,92 \\
Tingkat imigrasi penduduk & 3,55 \\
\hline
\end{tabular}

Sumber: Data Primer Desa Sebulu Modern (2019)

Tingkat emigrasi penduduk Desa Sebulu Modern adalah 5,92 hal ini menunjukkan bahwa setiap 1.000 penduduk terdapat 5 sampai 6 emigran. Tingkat imigrasi penduduk Desa Sebulu Modern adalah 3,55 yang artinya setiap 1.000 penduduk terdapat $3-4$ penduduk yang pindah.

b. Tingkat Kelahiran Bayi dan Tingkat Kematian Penduduk

Berdasarkan data Desa Sebulu Modern Tahun 20018, tingkat kelahiran bayi dan kematian penduduk disajikan dalam Tabel 9 di bawah ini

Tabel 9. Tingkat Kelahiran Bayi dan Kematian Penduduk Desa Sebulu Modern Tahun 20182019.

\begin{tabular}{lc}
\hline \multicolumn{1}{c}{ Keadaan Penduduk } & Keterangan \\
\hline Jumlah kelahiran bayi & 45 bayi \\
Jumlah kematian penduduk & 20 jiwa \\
Jumlah penduduk & 4.224 jiwa \\
Tingkal Kelahiran Bayi & 10,65 \\
Tingkat Kematian Penduduk & 4,73 \\
\hline
\end{tabular}

Sumber: Data Primer Desa Sebulu Modern (2019)

Berdasarkan tabel di atas, tingkat kelahiran bayi penduduk Sebulu Modern adalah 10,65 yang artinya setiap 1.000 penduduk terdapat 10 sampai 11 kelahiran bayi. Tingkat kematian penduduk Desa Sebulu Modern sebesar 4,73 yang artinya setiap 1.000 penduduk terdapat $4-5$ jiwa yang meninggal dunia.

3. Tenaga Kerja

a. Tingkat partisipasi angkatan kerja

Menurut aturan angkatan kerja produktif yang tertuang dalam Undang Undang Ketenagakerjaan No. 13 Tahun 2003 dan Undang Undang No. 11 Tahun 1992, serta mengacu data struktur penduduk berdasarkan umur, bahwa penduduk (Sebulu Modern) umur kerja yaitu 15 tahun ke atas sebanyak 2.947 jiwa.

Jumlah penduduk umur kerja yang bukan merupakan angkatan kerja di Sebulu Modern, dapat dilihat pada Tabel 10. di bawah ini.

Tabel 10. Penduduk Umur Kerja Bukan Angkatan Kerja Di Sebulu Modern.

\begin{tabular}{lc}
\hline \multicolumn{1}{c}{ Bukan Angkatan Kerja } & Keterangan \\
\hline $\begin{array}{l}\text { Hanya mengurus rumah } \\
\text { tangga dan tidak mau bekerja }\end{array}$ & 800 jiwa \\
$\begin{array}{l}\text { Umur kerja yang masih } \\
\text { sekolah/kuliah }\end{array}$ & 336 jiwa \\
$\begin{array}{l}\text { Jumlah penduduk yang tidak } \\
\text { mampu bekerja (manula yang } \\
\text { tidak mampu bekerja lagi dan } \\
\text { penduduk cacat fisik yang } \\
\text { tidak bisa bekerja) }\end{array}$ & 186 jiwa \\
\hline \multicolumn{1}{c}{ Jumlah } & 1.322 jiwa \\
\hline
\end{tabular}

Sumber: Data Primer Desa Sebulu Modern (2019)

Berdasarkan data pada tabel di atas, maka jumlah penduduk bukan angkatan kerja di Sebulu Modern sebanyak 1.322 jiwa.

Angkatan kerja penduduk Sebulu Modern adalah selisih dari jumlah penduduk usia 15 tahun ke atas dan jumlah penduduk bukan angkatan kerja yaitu 2.947 jiwa - 1.322 jiwa = 1.625 jiwa .

Dengan demikian tingkat partisipasi angkatan kerja (TPAK) penduduk Sebulu Modern adalah $55,14 \%$ dan tergolong rendah (rendah: TPAK $<64,13 \%$ dan tinggi: 
TPAK >64,13\%). Hal ini menunjukkan setiap 100 orang tenaga kerja terdapat 5556 orang angkatan kerja. Rendahnya TPAK Sebulu Modern disebabkan banyak ibu-ibu rumah tangga yang hanya mengurus rumah tangga dan tidak mau bekerja serta penduduk usia kerja yang masih sekolah/kuliah.

\section{b. Tingkat pengangguran.}

Jumlah angkatan kerja penduduk Sebulu Modern adalah 1.625 jiwa, jumlah penduduk yang bekerja/berusaha sebanyak 1.390 jiwa terdiri dari bekerja sebanyak 620 jiwa dan berusaha sebanyak 770 jiwa. Dengan demikian jumlah pengangguran di Sebulu Modern adalah 1.625 jiwa - 1.390 jiwa = 235 jiwa, maka tingkat pengangguran sebesar $14,46 \%$.

\section{B. Ekonomi}

\section{Tingkat Pendapatan Penduduk}

Untuk menghitung tingkat pendapatan penduduk dapat dilihat dari standar kebutuhan minimal hidup untuk setiap orang di lokasi studi yaitu Desa Sebulu Modern yang mengacu analisis kebutuhan pokok Provinsi Kalimantan Timur.

Dari data tersebut di atas, maka nilai kebutuhan minimum untuk setiap kapita selama setahun di lokasi studi adalah $\mathrm{Rp}$ 3.734.000,- perkapita pertahun.

Dari nilai tersebut dapat dikategorialkan sebagai berikut (Anonim, 2010) : a. Miskin sekali, bila pendapatan perkapita pertahun $<75 \%$ dari Rp. 3.734.000,atau lebih kecil dari Rp. 2.800.500,-

b. Miskin, bila pendapatan perkapita pertahun antara $75 \%$ sampai $125 \%$ dari Rp. 3.734.000,- atau Rp. 2.800.500,s/d. Rp. 4.667.500,-

c. Hampir miskin, bila pendapatan perkapita pertahun $>125 \%$ sampai $200 \%$ dari Rp 3.734.000,- atau > Rp. 4.667.500,- s/d. Rp. 7.468.000,-

d. Tidak miskin bila pendapatan perkapita pertahun > 200\% dari Rp. 3.734.000,atau > Rp 7.468.000,-

Berdasarkan data responden, rata-rata pendapatan perkeluarga perbulan penduduk yang dikelompokkan berdasarkan pekerjaan secara rinci dapat dilihat pada Tabel 12. Penentuan jumlah responden mengacu pada Hadi (2007)

Melihat tabel 12, maka rata-rata pendapatan perkeluarga penduduk Desa Sebulu Modern adalah Rp 4.133.333,/bulan. mengacu data pada struktur penduduk berdasarkan jenis kelamin dan kepadatan penduduk di atas, bahwa ratarata setiap KK Desa Sebulu Modern terdiri dari 3,58 jiwa. Dengan demikian rata-rata pendapatan perkeluarga penduduk tersebut setara dengan pendapatan penduduk perkapita pertahun sebesar Rp 13.854.747,50.

Tabel 11. Nilai Kebutuhan Minimum 9 Bahan Pokok/Kapita/Tahun Di Sebulu Modern

\begin{tabular}{lccc}
\hline \multicolumn{1}{c}{ Kebutuhan Pokok } & Volume & $\begin{array}{c}\text { Harga Satuan } \\
(\text { Rp })\end{array}$ & Nilai (Rp) \\
\hline Beras & $145 \mathrm{~kg}$ & 12.000 & 1.740 .000 \\
Ikan asin & $15 \mathrm{~kg}$ & 60.000 & 900.000 \\
Gula & $6 \mathrm{~kg}$ & 15.000 & 90.000 \\
Garam & $10 \mathrm{bks}$ & 2.000 & 20.000 \\
Minyak Goreng & $6 \mathrm{ltr}$ & 14.000 & 84.000 \\
Gas & $12 \mathrm{tabung}$ & 25.000 & 300.000 \\
Sabun & $20 \mathrm{bks}$ & 5.000 & 100.000 \\
Tekstil kasar & $4 \mathrm{~m}$ & 25.000 & 100.000 \\
Batik kasar & $12 \mathrm{~m}$ & 25.000 & 300.000 \\
\hline
\end{tabular}

Sumber: Data Primer Desa Sebulu Modern (2019) 
Tabel 12. Rata-rata Pendapatan Perkeluarga Penduduk Desa Sebulu Modern Berdasarkan Pekerjaan.

\begin{tabular}{lccc}
\hline \multicolumn{1}{c}{ Jenis Pekerjaan } & $\begin{array}{c}\text { Jumlah } \\
\text { Responden }\end{array}$ & $\begin{array}{c}\text { Rata-rata Penghasilan/ } \\
\text { Bulan (Rp) }\end{array}$ & $\begin{array}{c}\text { Jumlah } \\
(\mathrm{Rp})\end{array}$ \\
\hline Petani/nelayan sungai & 22 & 3.000 .000 & 66.000 .000 \\
Karyawan perusahaan & 4 & 6.500 .000 & 26.000 .000 \\
Wiraswasta/dagang & 16 & 6.000 .000 & 96.000 .000 \\
Tukang & 4 & 3.000 .000 & 12.000 .000 \\
Jasa & 5 & 3.000 .000 & 15.000 .000 \\
Aparatur sipil negara & 2 & 6.000 .000 & 12.000 .000 \\
Buruh lepas/honorer & 7 & 3.000 .000 & 21.000 .000 \\
\hline Jumlah & 60 & 248.000 .000 \\
\hline \multicolumn{2}{c}{ Rata-rata Pendapatan Perkeluarga Penduduk } \\
\hline
\end{tabular}

\section{Sumber: Data Primer Desa Sebulu Modern (2019)}

Keterangan: pekerjaan nelayan sungai merupakan pekerjaan sampingan.

Melihat tabel di atas, maka rata-rata pendapatan perkeluarga penduduk Desa Sebulu Modern adalah Rp 4.133.333,/bulan. mengacu data pada struktur penduduk berdasarkan jenis kelamin dan kepadatan penduduk di atas, bahwa ratarata setiap KK Desa Sebulu Modern terdiri dari 3,58 jiwa. Dengan demikian rata-rata pendapatan perkeluarga penduduk tersebut setara dengan pendapatan penduduk perkapita pertahun sebesar $\mathrm{Rp}$ 13.854.747,50.

Mengacu pada katagorial nilai kebutuhan minimum di atas, maka penduduk Sebulu Modern tergolong tidak miskin.

\section{Ekonomi Sumberdaya Alam}

a. Pola pemilikan dan penguasaan sumberdaya alam

Kepemilikan dan penguasaan lahan di Sebulu Modern mengacu pada penguasaan resmi yang dikuasai oleh lembaga resmi (pemerintah) serta diakui oleh penduduk lain. Kepemilikan lahan biasanya dilegalisasi dengan sertifikat atau surat kepemilihan lahan dari kecamatan dan tercatat di administrasi pemerintah. Atas kepemilikan tersebut, penduduk dapat memanfaatkan lahan sebagai pemukiman/pekarangan, ladang/kebun, dan lain sebagainya. Masyarakat memiliki/menguasai lahan dengan dua cara yaitu warisan dari orangtua, dan membeli lahan dari orang lain. b. Pola pemanfaatan sumberdaya alam

Lahan yang dimanfaatkan masyarakat Sebulu Modern adalah untuk pekarangan, perumahan, lahan usaha tani dan pemanfaatan lainnya. Pekarangan umumnya ditanami tanaman buah-buahan, pohon dan tempat beternak binatang peliharaan seperti ayam, bebek dan lainlain. Lahan usaha tani berupa sawah/ladang ditanami padi, jagung dan palawija (ketimun, cabe, terong, kacangkacangan, kunyit, singkong dan lain-lain), serta kebun ditanami pohon/tanaman buah-buahan seperti durian, lai, nangka, sukun, cempedak, langsat, pepaya, pisang, rambutan, mangga dan lain-lain.

Masyarakat petani yang menggarap lahan untuk kebun dan ladang dengan luasan yang bervariasi dari $0,5 \mathrm{Ha} / \mathrm{KK}$ hingga ada yang memiliki lebih dari 10 $\mathrm{Ha} / \mathrm{KK}$, namun yang paling banyak adalah petani yang memiliki lahan $\pm 1 \mathrm{Ha} / \mathrm{KK}$. Pembersihan lahan untuk ladang dan kebun sebelum ditanami, masih banyak yang dibuka dengan cara dibakar.

Pada umumnya pekerjaan petani ladang/kebun berhubungan langsung dengan sumber daya alam khususnya lahan usahatani yang jumlahnya 467 jiwa/KK atau 33,60\%. Dari gambaran tersebut dapat disimpulkan bahwa sifat ketergantungan masyarakat Desa Sebulu Modern terhadap sumber daya alam termasuk dalam kategori sedang (rendah: $<30 \%$, sedang: $30-50 \%$, dan tinggi: > $50 \%)$. 


\section{c. Pola penggunaan lahan}

Lahan yang dimanfaatkan penduduk Desa Sebulu Modern relatif sedikit dan lebih banyak lahan yang dikelola oleh perusahaan. Penggunaan lahan berdasarkan Profil Desa Sebulu Modern disajikan pada Tabel 13 berikut.

Tabel 13. Pola Penggunaan Lahan Di Desa Sebulu Modern

\begin{tabular}{lcc}
\hline \multicolumn{1}{c}{ Penggunaan Lahan } & $(\mathrm{Ha})$ & $(\%)$ \\
\hline Pemukiman dan & 100 & 1,60 \\
pekarangan & 1.500 & 23,94 \\
Sawah & 800 & 12,77 \\
Ladang/tegalan/kebun & & \\
Fasilitas dan & 2 & 0,03 \\
bangunan desa & 4 & 0,06 \\
Pekuburan & 0,25 & 0,002 \\
Pasar & 24 & 0,57 \\
Jalan desa & & \\
Perusahaan dan lahan & $3.836,5$ & 61,22 \\
\hline negara & $6.266,75$ & 100 \\
\hline Jumlah &
\end{tabular}

Sumber: Anonim (2019) dan Data Primer Desa Sebulu Modern (2019)

Desa Sebulu Modern memanfaatkan lahan untuk usahatani, pemukiman dan sarana prasarana desa sebesar $38,78 \%$ dan lainnya dikelola oleh perusahaan dan pemerintah.

3. Perekonomian Lokal dan Regional

a. Kesempatan kerja dan berusaha penduduk Sebulu Modern

Kesempatan kerja/berusaha penduduk Sebulu Modern merupakan prosentase dari jumlah penduduk yang bekerja/berusaha terhadap angkatan kerja penduduk tersebut.

Mengacu data tingkat partisipasi angkatan kerja dan data struktur penduduk berdasarkan pekerjaan pada uraian di atas, maka:

\section{1) Kesempatan Kerja}

Jumlah penduduk Sebulu Modern yang bekerja sebanyak 620 jiwa dan angkatan kerja sebanyak 1.625 jiwa, maka kesempatan kerja penduduk Sebulu Modern adalah 38,15\%.

\section{2) Kesempatan Berusaha}

Jumlah penduduk Sebulu Modern yang berusaha sebanyak 770 jiwa dan angkatan kerja sebanyak 1.625 jiwa, maka kesempatan berusaha penduduk Sebulu Modern adalah 47,38\%.

b. Pusat-pusat pertumbuhan ekonomi

Sarana dan prasarana ekonomi merupakan indikator pertumbuhan ekonomi. Sarana dan prasarana ekonomi yang ada di Desa Sebulu Modern secara lengkap dapat dilihat pada Tabel 14 di bawah ini.

Tabel 14. Sarana dan Prasarana Ekonomi Desa Sebulu Modern

\begin{tabular}{lc}
\hline $\begin{array}{c}\text { Sarana dan Prasarana } \\
\text { Ekonomi }\end{array}$ & Keterangan \\
\hline Jalan antar desa & $60 \mathrm{Km}$ \\
Pasar & $1 \mathrm{buah}$ \\
Pelabuhan & $3 \mathrm{buah}$ \\
Terminal kendaraan & Tidak ada \\
Angkutan umum & Tidak ada \\
Perbankan & 1 buah \\
Toko & 25 \\
Warung & 32 \\
Koperasi/bumdes $\quad 3$ \\
Jasa (pengiriman & Tidak ada \\
barang, travel, dll) & \\
Warnet/wartel & Tidak ada \\
Hotel/penginapan & Tidak ada \\
Destinasi wisata & Tidak ada \\
\hline
\end{tabular}

Sumber: Data Primer Desa Sebulu Modern (2019)

Berdasarkan data di atas, banyak sarana dan prasarana ekonomi yang tidak ada di Sebulu Modern. Dengan demikian pertumbuhan perekonomian Desa Sebulu Modern tergolong agak lambat.

c. Fasilitas umum, sosial dan pribadi masyarakat Sebulu Modern

Fasilitas umum, sosial dan pribadi masyarakat yang ada di Desa Sebulu Modern dapat dilihat pada Tabel 15 di bawah ini.

Tabel 15. Fasilitas Umum, Sosial dan Pribadi Masyarakat Di Desa Sebulu Modern.

\begin{tabular}{cc}
\hline Jenis Fasilitas & Keterangan \\
\hline Lapangan sepak bola & 2 buah \\
Lapangan bulutangkis & 2 buah
\end{tabular}




\begin{tabular}{lc}
\hline \multicolumn{1}{c}{ Jenis Fasilitas } & Keterangan \\
\hline Lapangan bola voly & 3 buah \\
Lapangan tenis meja & 2 buah \\
Puskesmas pembantu & 3 unit \\
Sekolahan & 21 unit \\
Gedung serbaguna & 1 buah \\
Gedung olahraga & 1 buah \\
Pos kamling & 15 buah \\
Sinyal telpon/internet & Kuat \\
Perpustakaan desa & 1 buah \\
Tempat ibadah & 7 buah \\
(masjid/mushala/gereja) & 1.200 buah \\
Televisi & 1.200 buah \\
Sepeda motor & 160 buah \\
Mobil &
\end{tabular}

Munir, I. 2014. Definisi Pekerjaan, Tenaga Kerja, Peluang Kerja, Pengangguran. Jakarta.

Sumber: Anonim (2019) dan Data Primer Desa Sebulu Modern (2019)

Berdasarkan data pada tabel di atas, maka fasilitas umum, sosial dan pribadi masyarakat yang dimiliki Desa Sebulu Modern tergolong cukup baik.

\section{KESIMPULAN}

Secara demografi Desa Sebulu Modern tergolong desa sedang dengan berstruktur muda, mayoritas agama pemeluk agama islam, merupakan desa agraris dan kehidupan tergantung sumber daya alam.

Secara ekonomi masyarakat Desa Sebulu Modern tergolong tidak miskin dengan kesempatan usaha tergolong tinggi namun pertumbuhan ekonominya rendah.

\section{DAFTAR PUSTAKA}

Ahmadi, A. 2003. Ilmu Sosial Dasar. Rineka Cipta. Jakarta

Anonim. 1960. Undang Undang no. 56 Tahun 1960 Tentang Agraria. Jakarta

Anonim. 2010. Badan Pusat Statistik Provinsi Kalimantan Timur, Samarinda.

Anonim. 2018. Data Kependudukan dan Profil Desa Sebulu Modern, Kecamatan Sebulu, Kabupaten Kutai Kartanegara. Tenggarong.

Hadi, A. 2007. Prinsip Pengelolaan Pengambilan Sampling Lingkungan. PT. Gramedia Pustaka Utama. Jakarta 